\title{
LC-MS/MS Method for Rapid Quantification of Progesterone in Rabbit Plasma and Its Application in a Pharmacokinetic Study of the Transdermal Formulation
}

\author{
Cao-Son Tran $\mathbb{D}^{1},{ }^{1}$ Quang-Dong Bui $\mathbb{D}^{1},{ }^{1}$ Ngoc-Tho Thi Nguyen, ${ }^{2}$ Minh-Hanh Dao, ${ }^{2}$ \\ and Thach-Tung Nguyen ${ }^{2}$ \\ ${ }^{1}$ Laboratory of Food Toxicology and Allergens Testing, National Institute for Food Control, Hanoi 10000, Vietnam \\ ${ }^{2}$ Department of Pharmaceutics, Hanoi University of Pharmacy, Hanoi 10000, Vietnam \\ Correspondence should be addressed to Cao-Son Tran; sontc@nifc.gov.vn
}

Received 25 August 2020; Revised 15 October 2020; Accepted 16 October 2020; Published 30 October 2020

Academic Editor: Tien Duc Pham

Copyright (C) 2020 Cao-Son Tran et al. This is an open access article distributed under the Creative Commons Attribution License, which permits unrestricted use, distribution, and reproduction in any medium, provided the original work is properly cited.

\begin{abstract}
A rapid and effective method using QuEChERS-based sample preparation procedure and liquid chromatography-tandem mass spectrometry (LC-MS/MS) analysis has been developed and validated to determine progesterone in rabbit plasma. The analyte was extracted from plasma by acetonitrile with phase partitioning by a mixture of magnesium sulfate and sodium chloride. The supernatant was then directly injected into LC-MS/MS in a positive electrospray ionization mode and quantified using progesterone- $\mathrm{d} 9$ as the internal standard. The method linearity was in the range from $1 \mathrm{ng} / \mathrm{mL}$ (LOQ) to $200 \mathrm{ng} / \mathrm{mL}$. Method recovery was from $86.0 \%$ to $103 \%$, and repeatability was lower than $5.5 \%$. The plasma sample was stable for 12 weeks stored at $18 \pm 2^{\circ} \mathrm{C}$. This method was applied to quantify progesterone in rabbit plasma in a pharmacokinetic study of two transdermal formulations: a reference drug and a eutectic-hydrogel system. The data indicate that the eutectic-hydrogel system's bioavailability was 1.5 times better than that of the reference drug, and the transdermal system is a potential drug delivery system for progesterone.
\end{abstract}

\section{Introduction}

Progesterone (Figure 1) is an endogenous steroid hormone secreted from the ovaries, testes, adrenal cortex, and placenta. It is the most critical hormone of progestins since this chemical has a crucial impact on the development of the uterus, fallopian tube, and breast [1]. Progesterone promotes cells to proliferate, enlarge, and become a secretary in nature [2]. The average serum progesterone level in adult women ranges from 0.15 to $25 \mathrm{ng} / \mathrm{mL}$, but it can reach $150 \mathrm{ng} / \mathrm{mL}$ during pregnancy $[3,4]$. This level in men and postmenopausal women was $0.38 \pm 0.13 \mathrm{ng} / \mathrm{ml}$ and $0.38 \pm 0.37 \mathrm{ng} / \mathrm{mL}$, derived from a study of Winkelmann et al. [5]. Progesterone has been indicated to contraception, implantation, breast cancer, autoimmune, or progesterone deficiency diseases [6-9]. The transdermal formulations of progesterone have been developed for contraception, breast cancer, and artificial insemination support $[7,10,11]$.
Some pharmacokinetic studies have evaluated the effectiveness of various formulations of progesterone [12-14], including the transdermal application [11]. Fraser et al., in an initial pharmacokinetic trial, evaluated the progesterone level in volunteers' blood after applying Nestorone ${ }^{\circledR}$, a spray formulation of progesterone. The study indicated that progesterone's serum level to block ovulation was achievable, and it can provide effective contraception [11]. However, the evidence which proves the transdermal application of progesterone is inadequate [10]. There is a need to study the progesterone's pharmacokinetics in the transdermal gel to evaluate its efficacy and safety.

Many methods have been used for analyzing progesterone in plasma. A conventional method for progesterone analysis is radioimmunoassay (RIA). Abraham et al. developed an RIA method to determine progesterone in plasma: the sensitivity varied from 10 to $25 \mathrm{pg}$, and the recovery was $84.2 \pm 4.8 \%$ [15]. Two enzyme immunoassay 


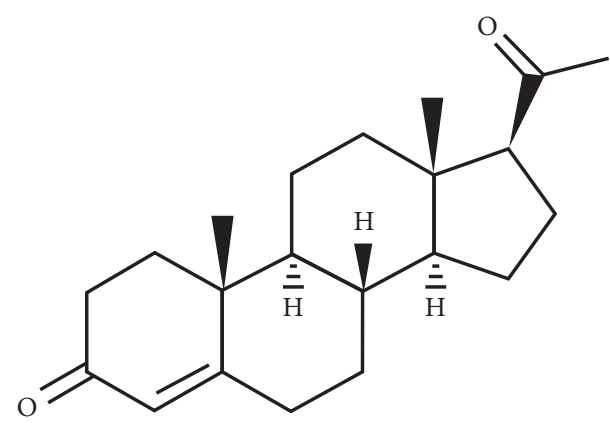

Figure 1: Chemical structure of progesterone.

(EIA) methods were developed using two different enzymes, horseradish peroxidase (HP) and alkaline phosphatase (AP), and were compared with RIA. The EIA-HP method's precision was comparable with the RIA method, and the detection limit was 10 times better than RIA. The EIA-AP method was not suitable to determine progesterone in the plasma because the value of this assay was three times higher than those measured by the other methods. Although RIA and EIA methods have their pros for high specificity and sensitivity, its cons are present in complexity in its cost and instruments [16].

Liquid chromatography-tandem mass spectrometry (LC-MS/MS) has recently become a widely used method to determine progesterone in biological matrices. Tai et al. developed a liquid-liquid extraction followed by LC-MS/MS analysis to quantify progesterone in human serum. Progesterone and the internal standard (progesterone- ${ }^{13} \mathrm{C} 2$ ) were duplicate extracted into $n$-hexane. The extract was then dried under nitrogen and reconstituted in methanol containing acetic acid before directly injected into LC-MS/MS. The method was successfully validated in the range from 0.151 to $24.42 \mathrm{ng} / \mathrm{g}$ [17]. Fernandes et al. applied a similar procedure in cattle plasma using medroxyprogesterone acetate as the internal standard and compared it to the RIA method. The LC-MS/MS method gave a higher progesterone concentration than the RIA method, explaining that the RIA method is affected by interferences in the matrix [18]. Zhang et al. used solid-phase extraction with Oasis HLB cartridge prior to LC-MS/MS analysis to determine $17 \alpha$-hydroxyprogesterone caproate, $17 \alpha$-hydroxyprogesterone, and progesterone in human plasma with medroxyprogesterone acetate as the internal standard. The linearity of progesterone was from 1 to $200 \mathrm{ng} / \mathrm{mL}$ [14]. Sasaki et al. employed saltingout assisted liquid-liquid extraction with LC-MS/MS for progesterone analysis to obtain easier and quicker sample preparation steps. With ammonium acetate as the saltingout agent, this method was applied to analyze progesterone in rat plasma from 0.05 to $20 \mathrm{ng} / \mathrm{mL}$. The heavy matrix effect was controlled using the calibration curve on the surrogate matrix (water) [13].

Plasma analysis requires a method that is high throughput and appropriate for a limited amount of plasma. QuEChERS methodology, invented by Anastassiades and Lehotay for multiresidue analysis of pesticides [19], has been applied in extracting various pharmaceutical compounds in plasma matrices [20-23]. Intending to develop a method that is quick and uses less solvent as well as to evaluate the pharmacokinetic study of progesterone from the transdermal route, this paper presents a rapid QuEChERS-based method coupled with LC-MS/MS for the quantification of progesterone in rabbit plasma.

\section{Materials and Methods}

2.1. Standards, Reagents, and Materials. Progesterone analytical standard and isotope internal standard (progesteroned9) were purchased from Sigma-Aldrich (St. Louis, MO, USA). Acetonitrile, ethanol, formic acid, ammonium chloride, anhydrous magnesium sulfate, and sodium chloride were obtained from Merck Vietnam (Hanoi, Vietnam). Ultrapure water was produced by a water filtration system (Milli-Q ${ }^{\circledR}$ Integral, Merck, Germany).

The progesterone and progesterone-d9 stock solutions, both of $100 \mu \mathrm{g} / \mathrm{mL}$, were separately prepared in ethanol. The stock solutions were then diluted with acetonitrile to the concentrations of $1 \mu \mathrm{g} / \mathrm{mL}$. The matrix-matched calibration curve was prepared in the blank extract with the progesterone concentration in the range of 1 to $200 \mathrm{ng} / \mathrm{mL}$ and progesterone-d9 concentration of $50 \mathrm{ng} / \mathrm{mL}$.

The eutectic hydrogel of progesterone (EHP) was prepared in the Department of Pharmaceutics, Hanoi University of Pharmacy (obtained from another study). The reference drug formulation (RDF) was $1 \%$ progesterone gel (Besins Manufacturing, Belgium), which was purchased in the market.

2.2. Plasma Preparation. Rabbit plasma was brought to room temperature, and $500 \mu \mathrm{L}$ was pipetted into $2 \mathrm{~mL}$ centrifuged tube followed by the addition of $25 \mu \mathrm{L}$ internal standard solution of $1 \mu \mathrm{g} / \mathrm{mL}$ and $475 \mu \mathrm{L}$ of acetonitrile. After being vigorously shaken by a vortex mixer, the tube received a mixture of salts and sorbents (described below), and it was mixed thoroughly for $1 \mathrm{~min}$. The tube was then centrifuged at 13,000 rpm in 5 mins, and the supernatant was passed through a $0.2 \mu \mathrm{m}$ PTFE filter and analyzed by LC-MS/ MS.

The composition of salting-out and cleaning agents will be accessed by comparing the efficiency of different mixtures of salts and sorbents: (1) $200 \mathrm{mg}$ of $\mathrm{MgSO}_{4}$, (2) $150 \mathrm{mg}$ of $\mathrm{MgSO}_{4}$ and $50 \mathrm{mg}$ of $\mathrm{NaCl}$, (3) $150 \mathrm{mg}$ of $\mathrm{MgSO}_{4}$ and $50 \mathrm{mg}$ of PSA, (4) $150 \mathrm{mg}$ of $\mathrm{MgSO}_{4}$ and $50 \mathrm{mg}$ of C18, (5) $200 \mathrm{mg}$ of $\mathrm{CH}_{3} \mathrm{COONH}_{4}$, and (6) $200 \mathrm{mg}$ of $\mathrm{NH}_{4} \mathrm{Cl}$.

The blank sample was extracted via the abovementioned procedure without adding IS in the first step. The final extract was used to prepare working standard solutions at the concentration from 1 to $200 \mu \mathrm{g} / \mathrm{mL}$ (for progesterone) and $50 \mu \mathrm{g} / \mathrm{mL}$ (for progesterone-d9).

2.3. Instrumentation. An LC 1290 coupled with a 6460 QQQ mass spectrometer (Agilent, USA) was used to determine progesterone and progesterone- $\mathrm{d} 9$. The analytes were separated in Eclipse plus Agilent XD8 C18 column $(150 \times 2.1 \mathrm{~mm}, 3.5 \mu \mathrm{m}$ particle size $)$ with the mobile phase of 
deionized water (A) and acetonitrile (B); both contained $0.1 \%$ of formic acid, at the flow rate of $0.5 \mathrm{~mL} /$ minute. The gradient program was initially set at $10 \% \mathrm{~B}$ in 2 minutes. After that, the eluent composition gradually increases to $90 \%$ $\mathrm{B}$ in 2.5 minutes and maintains 4 minutes before returning to $10 \%$ in 1 minute. The system was finally reequilibrated in 2 minutes before the next injection.

The electrospray ionization source was operated in the positive mode to select the precursor ion. The collision energies were optimized to obtain the most abundant product ions. Two transitions of each compound were observed, of which the product mass with a higher intensity was chosen for the quantitative purpose, and the other mass was used for the confirmation purpose.

2.4. Method Validation. The method was validated according to the guideline for the bioanalytical method validation of the US FDA [24]. The specificity was assessed by comparing the chromatograms of the blank sample, the standard solution of $50 \mu \mathrm{g} / \mathrm{mL}$, and the blank sample spiked with progesterone and progesterone- $\mathrm{d} 9$ at the concentration of $50 \mu \mathrm{g} / \mathrm{mL}$. The noise ratio $(\mathrm{S} / \mathrm{N})$ methodology was applied to estimate the limit of detection (LOD) and limit of quantification (LOQ). The progesterone levels in blank spiked samples having $\mathrm{S} / \mathrm{N}$ ratios of 3 and 10 were LOD and LOQ, respectively. Repeatability and recovery were evaluated by analyzing 6 replicates of spiked samples of three concentration levels: low-quality control (LQC) at $1 \mu \mathrm{g} / \mathrm{mL}$, medium-quality control (MQC) at $50 \mu \mathrm{g} / \mathrm{mL}$, and highquality control at $200 \mu \mathrm{g} / \mathrm{mL}$.

Because of the low photochemical stability of progesterone, the long-term stability of the plasma sample was evaluated following the recommendation of the US FDA [24]. The blank rabbit plasma samples were spiked with progesterone at 2 concentrations of LQC and HQC. The first lot was analyzed in 6 replicates to determine the initial concentration. The remaining lots were stored at $-18^{\circ} \mathrm{C} \pm 2^{\circ} \mathrm{C}$ and were tested after 1 week, 2 weeks, 4 weeks, 8 weeks, and 12 weeks. The bias of the average concentration of each lot to the initial concentration should be within $15 \%$.

2.5. Application in Pharmacokinetic Study. The animal study was approved by the Scientific and Ethics Committee, Hanoi University of Pharmacy. Male rabbits of about $2 \mathrm{~kg}$ each, purchased from the Centre of Experimental Animals, National Institute of Hygiene and Epidemiology (Hanoi, Vietnam), were selected for pharmacokinetic study. Male rabbits were chosen for pharmacokinetic experiments to avoid high fluctuating progesterone levels in female individuals. They were divided into two groups of three: one group for the reference drug and the other for the eutectic hydrogel system containing progesterone. Each gel $(2.5 \mathrm{~g})$ was applied to skin-free fur $(5 \mathrm{~cm} \times 10 \mathrm{~cm})$ on the back of the rabbits. The blood samples $(2 \mathrm{~mL})$ were collected before applying the drug and at 4 hours, 6 hours, 7 hours, 9 hours, and 10 hours after the administration into an EDTA-coated tube. The tubes were centrifuged at $6000 \mathrm{rpm}$ in 10 minutes, and the plasmas were collected and stored in $2 \mathrm{~mL}$ tubes at $-10 \mathrm{C}$ before being injected into LC-MS/MS.

The Phoenix 8 software was used to calculate the pharmacokinetic parameters, including the maximum plasma concentration $\left(C_{\max }\right)$, the time until $C_{\max }$ is reached $\left(T_{\max }\right)$, and the area under the curve from time zero to ten hours (AUC0-10 h).

\section{Results and Discussion}

3.1. Optimization of Mass Spectrometry Condition. The ion transitions of progesterone and progesterone- $\mathrm{d} 9$ were obtained by directly infusing the standard solution of $1 \mu \mathrm{g} / \mathrm{mL}$ into the mass spectrometer. The precursor ions were obtained when the molecular ion combined with a proton. The optimal collision energies were selected for two product ions (Table 1). Other mass spectrometer parameters were selected to gain the highest intensities of the analytes. Under these conditions, progesterone and progesterone- $\mathrm{d} 9$ peaks, both with a retention time of around $4.9 \mathrm{~min}$, were symmetric and sufficient to the analysis (Supplement Figure S1).

3.2. Selection of Salting-Out Agents. The average intensities of peak area in spiked samples $(n=2)$ and working standard solutions of the same concentration $(50 \mu \mathrm{g} / \mathrm{mL})$ were compared to select the most effective partitioning and cleaning mixtures. The results are introduced in Figure 2.

The use of $\mathrm{CH}_{3} \mathrm{COONH}_{4}$ and $\mathrm{NH}_{4} \mathrm{Cl}$ gave the highest recovery of progesterone and progesterone- $\mathrm{d} 9$. However, the values of higher than $100 \%$ recovery indicate that the two layers are not completely separated: the amount of acetonitrile layer was less than the aqueous layer. The recovery when using $\mathrm{MgSO}_{4}$ was low because some water might still be in the acetonitrile layer. Although the salting-out assisted liquid/liquid extraction (SALLE), described by Sasaki et al. [13], used $\mathrm{CH}_{3} \mathrm{COONH}_{4}$ as a salting-out agent, this study showed that using $\mathrm{CH}_{3} \mathrm{COONH}_{4}$ will result in incomplete separation between aqueous and organic phase.

The QuEChERS extraction consists of two steps: first, the compound is usually extracted into acetonitrile from the water phase with the help of salting-out agents, and second, the extract is cleaned up by dispersive solid-phase extraction. Since the amount of plasma is limited, the second step was omitted, and the sorbents were added into the first step to investigate the cleaning efficiency. However, neither PSA nor C18 sorbent helped increase the recovery of progesterone. The combination of $\mathrm{MgSO}_{4}$ and $\mathrm{NaCl}$ gave the best extraction recovery of $105 \%$ and $91 \%$ for progesterone and progesterone- $\mathrm{d} 9$, respectively, and was chosen to be the salting-out agents in this extraction procedure.

3.3. Method Validation. The method specificity was accessed by comparing chromatograms of the blank sample, spiked sample at $50 \mathrm{ng} / \mathrm{mL}$, and standard solution of $50 \mathrm{ng} / \mathrm{mL}$ (data shown in Supplements). There is no interference in the blank sample compared to the progesterone peak in the spiked sample and standard solution. Furthermore, the specificity was also supported by accessing the ion ratios of 
TABLE 1: Multiple reaction monitoring conditions of progesterone and progesterone- $\mathrm{d} 9$.

\begin{tabular}{lccc}
\hline Analytes & Precursor ion $(\mathrm{m} / z)$ & Product ion $(\mathrm{m} / z)$ & Collision energy, eV \\
\hline Progesterone & 315.2 & $109^{\mathrm{a}}$ & 30 \\
\hline \multirow{2}{*}{ Progesterone-d9 } & 324.3 & 97 & 26 \\
\hline
\end{tabular}

${ }^{\mathrm{a}}$ Quantitative ion.

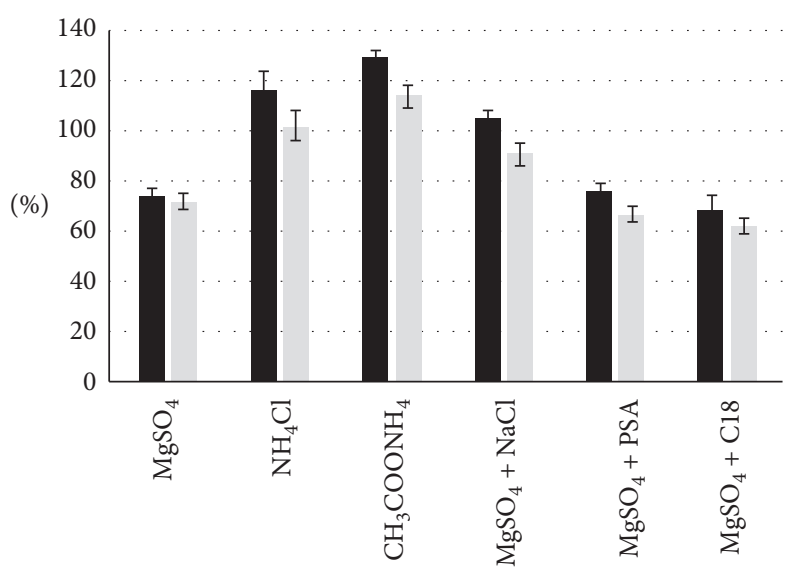

Progesterone

Progesterone-d9

FIGURE 2: Progesterone and progesterone-d9 extraction recovery of different salting-out agents.

progesterone and progesterone-d9 (both about 100\%) of the samples to those of the standards (Supplement Figure S1).

LOD and LOQ were determined by calculating the S/N ratio in low-concentration spiked sample analysis (Supplement Figure S2). The LOD and LOQ were at 0.3 and $1 \mathrm{ng} /$ $\mathrm{mL}$, respectively, which were low enough for determining progesterone concentration in rabbit plasma. The LOD of the method was not as low as that of Sasaki's study [13], but it is fit for the purpose of analyzing the level of progesterone in plasma, which is usually higher than $1 \mathrm{ng} / \mathrm{mL}$. The method was linear from 1 to $200 \mathrm{ng} / \mathrm{mL}$ with the coefficient of determination $\left(R^{2}\right)$ being higher than 0.99 (Figure 3).

The repeatability and recovery of progesterone at three concentrations $(n=6)$ are presented in Table 2 . The method is precise and accurate, with the relative standard deviation lower than $5.5 \%$ and the recovery from $86.0 \%$ to $103 \%$. This method was proven to meet the US FDA's requirements, had very high throughput (10 minutes to complete a set of 6 samples), and was environmental friendly (less than $0.5 \mathrm{~mL}$ of solvent for one extraction). These results indicate that the method can be a useful tool for pharmacokinetics studies of progesterone.

The stability of the plasma sample stored at $18^{\circ} \mathrm{C} \pm 2^{\circ} \mathrm{C}$ within 12 weeks is introduced in Figure 4. Through 12

weeks, the difference in concentration of the analyte in the plasma and the original concentration sample had not exceeded $15 \%$ for both HQC and LQC levels. The RSD value between the quantitative concentrations of each QC batch at the time of analysis was less than 15\%. These results demonstrate that the plasma sample is stable for at least 12 weeks with the proper storage condition.

3.4. Pharmacokinetic Study. The $T_{\max }$ of the reference drug and the eutectic-hydrogel system (Table 3) was similar (6.33 hours and 6.67 hours) following the drug's pharmacokinetics through the skin: it takes several hours to reach the peak in plasma. This is because the drug has to undergo dissolution and absorption through the skin followed by the distribution, metabolism, and elimination process. The $C_{\max }$ of the eutectic-hydrogel system was higher than that of the reference drug, but it was not statistically different $(p=0.13)$. Relative bioavailability data showed that the area under the curve from time zero to ten hours $\left(\mathrm{AUC}_{0-10 \mathrm{~h}}\right.$ ) of the eutectic-hydrogel system was about 1.5 times higher than that of the reference drug (Table 3 and Figure 5).

The pharmacokinetics of progesterone on the rabbit has not yet been reported before. Compared with the study on volunteers of Fraser [11], the $\mathrm{T}_{\max }$ of this study (6.33 to 6.67 hours) was lower than that of the single-dose application (20 hours) but higher than that of the multiple-dose treatment (4 hours) of a spray formulation. Because of the pharmacokinetic differences between species, the $C_{\max }$ value was incomparable.

This pharmacokinetic study may be affected by the limited number of rabbits used in this study. The standard 


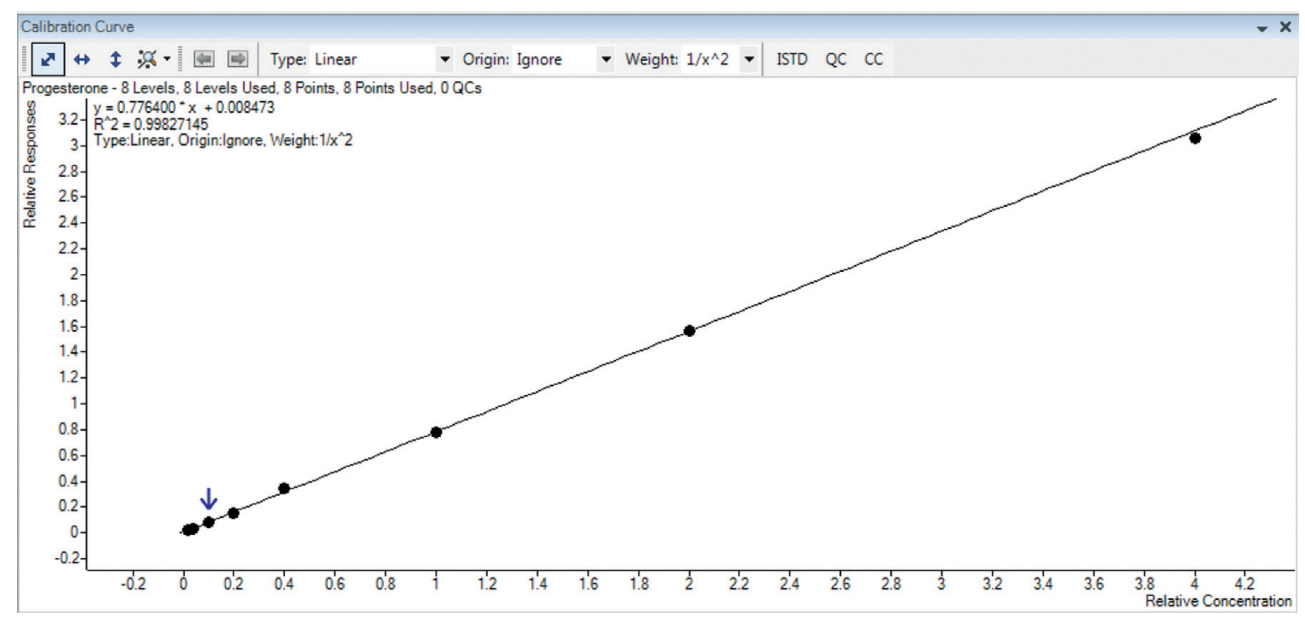

FIGURE 3: The calibration curve of progesterone on blank matrix.

TABLE 2: Repeatability and recovery of progesterone at different levels.

\begin{tabular}{lcc}
\hline Spiked level $(\mathrm{ng} / \mathrm{mL})$ & RSD $(\%)$ & R (\%) \\
\hline 1 & 5.5 & $86.0-100$ \\
50 & 1.7 & $98.6-103$ \\
200 & 2.8 & $97.3-102$ \\
\hline
\end{tabular}

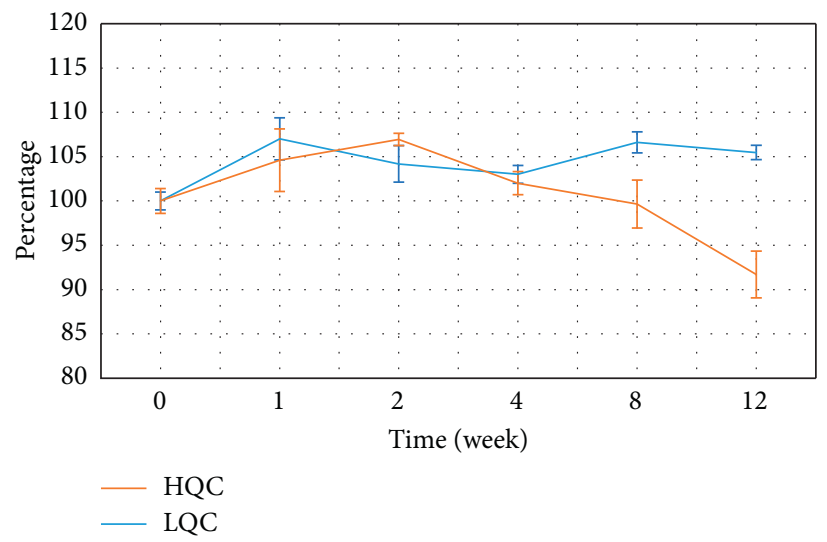

FIGURe 4: The stability of plasma sample spiked at two levels (LQC and HQC) within 12 weeks stored at $-18^{\circ} \mathrm{C} \pm 2^{\circ} \mathrm{C}$.

TABLE 3: Pharmacokinetic parameters of progesterone on rabbit models.

\begin{tabular}{lcc}
\hline Parameter & Eutectic-hydrogel system $( \pm \mathrm{SD})$ & Reference drug formulation $( \pm \mathrm{SD})$ \\
\hline$C_{\max }(\mathrm{ng} / \mathrm{mL})$ & $11.1 \pm 0.66$ & $8.49 \pm 3.32$ \\
$T_{\max }(\mathrm{h})$ & $6.67 \pm 0.58$ & $6.33 \pm 0.58$ \\
$\mathrm{AUC}_{0-10 \mathrm{~h}}(\mathrm{ng} . \mathrm{h} / \mathrm{mL})$ & $69.0 \pm 6.49$ & $46.5 \pm 21.9$ \\
\hline
\end{tabular}

deviations of some points in the pharmacokinetic curve of three cases were high (Figure 5), and it may change the actual values of pharmacokinetic parameters. Future studies may be needed with a larger number of objects and a longer time of sample collection. However, the trend of the curves is unaffectable, these results substantiate the transdermal gel of progesterone, and this formulation can be a potential route for future progesterone application. 


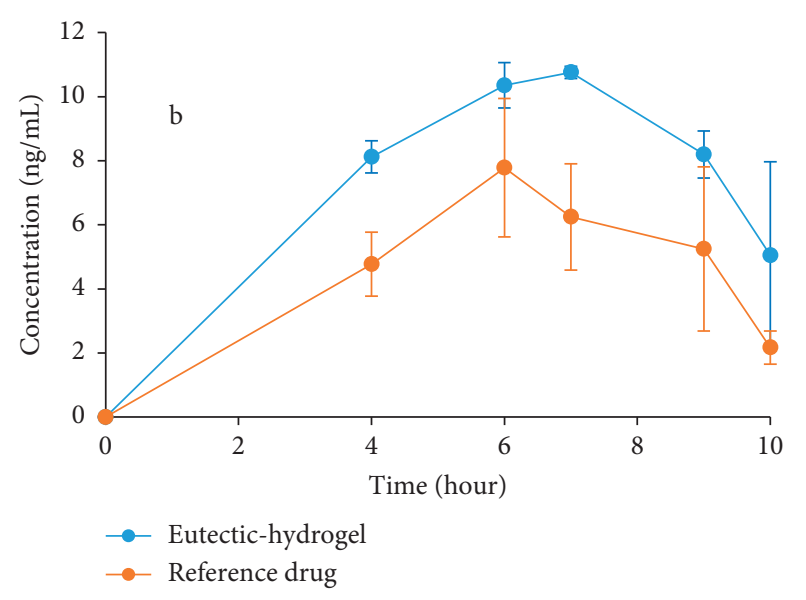

FIgURe 5: Progesterone content in rabbit plasma after applying the transdermal gels.

\section{Conclusions}

We have validated a rapid and effective QuEChERS-based method to determine progesterone in rabbit plasma using liquid chromatography-tandem mass spectrometry. The method uses less organic solvent than conventional liquidliquid extraction or solid-phase extraction methods and has suitable sensitivity and accuracy to quantify the progesterone concentration in plasma. The progesterone level in plasma was stable within 12 weeks of evaluation. The pharmacokinetics study showed a similar pattern of the pharmacokinetics of two transdermal formulations, and the eutectic-hydrogel system is proven to be a potential application of progesterone.

\section{Data Availability}

The main part of the research data is included in the article. The chromatograms are included in the supplement file. Other data can be made available from the corresponding author upon request.

\section{Conflicts of Interest}

The authors declare that there are no conflicts of interest.

\section{Acknowledgments}

This research was funded by the National Institute for Food Control in 2018.

\section{Supplementary Materials}

Figure S1: the chromatograms of standard solution of progesterone and progesterone- $\mathrm{d} 9$ (both of $50 \mathrm{ng} / \mathrm{mL}$ ) with two ion transitions for each compound. Figure S2: chromatograms of progesterone in (a) working standard solution of $50 \mathrm{ng} / \mathrm{mL}$, (b) blank sample spiked at $50 \mathrm{ng} / \mathrm{mL}$, (c) blank sample, and (d) blank sample spiked at $1 \mathrm{ng} / \mathrm{mL}$ (LOQ). (Supplementary Materials)

\section{References}

[1] M. B. Aufrère and H. Benson, "Progesterone: an overview and recent advances," Journal of Pharmaceutical Sciences, vol. 65, no. 6, pp. 783-800, 1976.

[2] I. M. Spitz, "Progesterone antagonists and progesterone receptor modulators: an overview," Steroids, vol. 68, no. 10, pp. 981-993, 2003.

[3] E. Carmina, F. Z. Stanczyk, and R. A. Lobo, "Laboratory assessment," in Yen \& Jaffe's Reproductive Endocrinologypp. 822-850, Philadelphia, PA, USA, 7th edition, 2014.

[4] P. Kumar and N. Magon, "Hormones in pregnancy," Nigeria Medical Journal, vol. 53, no. 4, pp. 179-183, 2012.

[5] B. R. Winkelmann, "Rationale and design of the LURIC study - a resource for functional genomics, pharmacogenomics and longterm prognosis of cardiovascular disease," Pharmacogenomics, vol. 2, no. 1, pp. S1-S73, 2001.

[6] B. A. Lessey, "Two pathways of progesterone action in the human endometrium: implications for implantation and contraception," Steroids, vol. 68, no. 10, pp. 809-815, 2003.

[7] M. Brkic, "The influence of progesterone gel therapy in the treatment of fibrocystic breast disease," Open Journal of Obstetrics and Gynecology, vol. 6, no. 5, 2016.

[8] S. Dv and P. Mc, "Sex steroids and breast cancer prevention," Journal of National Cancer Institute Monograph, vol. 16, pp. 139-147, 1994.

[9] G. C. Hughes, "Progesterone and autoimmune disease," Autoimmunity Reviews, vol. 11, no. 6, 2012.

[10] X. Ruan and A. O. Mueck, "Systemic progesterone therapy-oral, vaginal, injections and even transdermal?" Maturitas, vol. 79, no. 3, pp. 248-255, 2014.

[11] I. S. Fraser, "An initial pharmacokinetic study with a metered dose transdermal system ${ }^{\circledR}$ for delivery of the progestogen nestorone ${ }^{\circledR}$ as a possible future contraceptive," Contraception, vol. 76, no. 6, pp. 432-438, 2007.

[12] R. Sitruk-Ware, C. Bricaire, B. De Lignieres, H. Yaneva, and P. Mauvais-Jarvis, "Oral micronized progesterone: bioavailability pharmacokinetics, pharmacological and therapeutic implications-a review," Contraception, vol. 36, no. 4, pp. 373-402, 1987.

[13] M. Sasaki, H. Ochiai, K. Takahashi, R. Suzuki, K. Minato, and A. Fujikata, "Development and validation of LC-MS/MS assay for the quantification of progesterone in rat plasma and its application to pharmacokinetic studies," Drug Res (Stuttg), vol. 65, no. 9, pp. 484-489, 2015.

[14] S. Zhang, "Simultaneous quantitation of $17 \alpha$-hydroxyprogesterone caproate, $17 \alpha$-hydroxyprogesterone and progesterone in human plasma using high-performance liquid chromatography-mass spectrometry (HPLC-MS/MS)," Journal of Pharmaceutical and Biomedical Analysis, vol. 48, no. 4, pp. 1174-1180, 2008.

[15] G. E. Abraham, R. Swerdloff, D. Tulchinsky, and W. D. Odell, "Radioimmunoassay of plasma progesterone," The Journal of Clinical Endocrinology and Metabolism, vol. 32, no. 5, pp. 619-624, 1971.

[16] B. S. Prakash, H. H. D. Meyer, E. Schallenberger, and D. F. M. van De Wiel, "Development of a sensitive enzymeimmunoassay (EIA) for progesterone determination in unextracted bovine plasma using the second antibody technique," Journal of Steroid Biochemistry, vol. 28, no. 6, pp. 623-627, 1987.

[17] S. S.-C. Tai, B. Xu, and M. J. Welch, "Development and evaluation of a candidate reference measurement procedure for the determination of progesterone in human serum using 
isotope-dilution liquid chromatography/tandem mass spectrometry," Analytical Chemistry.vol. 78, no. 18, pp. 66286633, 2006.

[18] R. M. T. Fernandes, "LC-MS/MS quantitation of plasma progesterone in cattle," Theriogenology, vol. 76, no. 7, pp. 1266-1274, 2011.

[19] M. Anastassiades, S. J. Lehotay, D. Štajnbaher, and F. J. Schenck, "Fast and easy multiresidue method employing acetonitrile extraction/partitioning and 'dispersive solidphase extraction' for the determination of pesticide residues in produce," Journal of AOAC International, vol. 86, no. 2, pp. 412-431, 2003.

[20] S. G. Lee, "Development of a comprehensive analytical method for furanocoumarins in grapefruit and their metabolites in plasma and urine using UPLC-MS/MS: a preliminary study," International Journal of Food Sciences and Nutrition, vol. 67, no. 8, pp. 881-887, 2016.

[21] F. S. Jahed, S. Hamidi, S. Ghaffary, and B. Nejati, "Dispersive micro solid phase extraction of busulfan from plasma samples using novel mesoporous sorbent prior to determination by HPLC-MS/MS," Journal of Chromatography B, vol. 1145, Article ID 122091, 2020.

[22] M. Mülek and P. Högger, "Highly sensitive analysis of polyphenols and their metabolites in human blood cells using dispersive SPE extraction and LC-MS/MS," Anal Bioanalytical Chemistry, vol. 407, no. 7, pp. 1885-1899, 2015.

[23] S. C. Tran, N. D. Duc, and N.-T. Tung, "Pharmacokinetic analysis of levo-tetrahydropalmatine in rabbit plasma by rapid sample preparation and liquid chromatography-tandem mass spectrometry," Journal of Chromatography B, vol. 1008, pp. 81-86, 2016.

[24] USFDA, Bioanalytical Method Validation Guidance for Industry, US Department of Health and Human Services Food and Drug Administration Center for Drug Evaluation and Research and Center for Veterinary Medicine, Washington,DC, USA, 2018. 